\title{
The impact of obesity on cardiac troponin levels after prolonged exercise in humans
}

\author{
Thijs M. H. Eijsvogels • Matthijs T. W. Veltmeijer • \\ Keith George • Maria T. E. Hopman • \\ Dick H. J. Thijssen
}

Received: 21 March 2011 / Accepted: 19 August 2011 / Published online: 4 September 2011

(c) The Author(s) 2011. This article is published with open access at Springerlink.com

\begin{abstract}
Elevated cardiac troponin I (cTnI), a marker for cardiac damage, has been reported after high-intensity exercise in healthy subjects. Currently, little is known about the impact of prolonged moderate-intensity exercise on cTnI release, but also the impact of obesity on this response. 97 volunteers ( 55 men and 42 women), stratified for BMI, performed a single bout of walking exercise $(30-50 \mathrm{~km})$. We examined cTnI-levels before and immediately after the exercise bout in lean $\left(\mathrm{BMI}<25 \mathrm{~kg} / \mathrm{m}^{2}\right.$, $n=30,57 \pm 19$ years), overweight $\left(25 \leq \mathrm{BMI}<30 \mathrm{~kg} / \mathrm{m}^{2}\right.$, $n=29,56 \pm 11$ years), and obese subjects (BMI $\geq 30 \mathrm{~kg}$ / $\mathrm{m}^{2}, n=28,53 \pm 9$ years). Walking was performed at a selfselected pace. cTnI was assessed using a high-sensitive cTnI-assay (Centaur; clinical cut-off value $\geq 0.04 \mu \mathrm{g} / \mathrm{L}$ ). We recorded subject characteristics (body weight, blood pressure, presence of cardiovascular risk) and examined exercise intensity by recording heart rate. Mean cTnI-levels increased significantly from $0.010 \pm 0.006$ to $0.024 \pm$ $0.046 \mu \mathrm{g} / \mathrm{L}(P<0.001)$. The exercise-induced increase in cTnI was not different between lean, overweight and obese subjects (two-way ANOVA interaction; $P=0.27$ ). In 11 participants, cTnI was elevated above the clinical cut-off value for myocardial infarction. Logistic regression analysis
\end{abstract}

Communicated by Susan A. Ward.

T. M. H. Eijsvogels · M. T. W. Veltmeijer · M. T. E. Hopman

D. H. J. Thijssen

Department of Physiology, Radboud University Nijmegen

Medical Centre, Nijmegen, The Netherlands

e-mail: t.eijsvogels@fysiol.umcn.nl

K. George · D. H. J. Thijssen ( $\square)$

Research Institute for Sport and Exercise Science,

Liverpool John Moores University, 15-21 Webster Street,

Liverpool L3 2ET, UK

e-mail: d.thijssen@1jmu.ac.uk identified exercise intensity $(P<0.001)$, but not BMI, body fat percentage or waist circumference to significantly relate to positive troponin tests. In conclusion, prolonged, moderate-intensity exercise results in a comparable increase in cTnI-levels in lean, overweight and obese subjects. Therefore, measures of obesity unlikely relate to the magnitude of the post-exercise elevation in cTnI.

Keywords Troponin - Cardiac damage $\cdot$ Exercise $\cdot$ Cardiovascular pathology $\cdot$ Obesity

\section{Introduction}

The presence of intracellular cardiac troponin subunits $\mathrm{T}$ and I (cTnT and cTnI) in the blood is a sensitive and specific indicator for myocardial injury (Thygesen et al. 2007; $\mathrm{Wu}$ 2009), whilst elevated cTn levels play a central role in the diagnosis of acute myocardial infarction (AMI) (Kragelj et al. 2000; Thygesen et al. 2007). Previous studies have also reported release of circulating $\mathrm{cTnT} / \mathrm{cTnI}$ concentrations after prolonged exercise, with cTn levels even exceeding the cut-off level typically used for the diagnosis of AMI (Eijsvogels et al. 2010; Koller 2003; Neumayr et al. 2005; Shave et al. 2007a, 2010; Whyte et al. 2007; Wu 2009).

Previous studies indicated that cardiovascular risk factors are associated with higher baseline cTn-levels under resting conditions (Wallace et al. 2006). Interestingly, recent clinical and epidemiological studies have demonstrated that these elevated resting cTn levels are predictive of all-cause mortality (Daniels et al. 2008; de Lemos et al. 2010; Saunders et al. 2011) and future cardiovascular disease (Daniels et al. 2008; Everett et al. 2011; Saunders et al. 2011) in the selected patient groups as well as in the 
general population. If cTnI levels are higher at baseline, cTnI levels may rise even more under demanding conditions such as exercise. Therefore, subjects with increased cardiovascular risk may demonstrate a larger exerciseinduced increase in cTnI compared to healthy controls.

Obesity represents an important and common cardiovascular risk factor (Gelber et al. 2008), whilst the prevalence of obesity is still rising (across all ages) and affecting both the developed and developing world (James 2008). Some previous studies found that measures of obesity, such as body mass index, may be associated with higher resting cTn-levels in the general public (de Lemos et al. 2010; Saunders et al. 2011). However, it is currently unknown whether obesity alters the exercise-induced troponin release. This is of special importance as exercise training is routinely prescribed as an effective strategy to lose weight to individuals with obesity. Therefore, we assessed the effect of obesity on cardiac troponin release after prolonged moderate-intensity exercise. We measured cTnI concentrations in lean, overweight and obese subjects with comparable training status before and immediately after a single bout of prolonged exercise. For this purpose, we examined changes in absolute cTnI-levels, identified those with an elevation in cTnI above the cut-off value for acute myocardial infarction, and examined whether these post-exercise cTnI-levels were related to obesity or to other individual or exercise-related factors. We hypothesize to find higher cTnI levels in obese compared to overweight and lean subjects.

\section{Methods}

\section{Subjects}

Ninety-seven participants were included and stratified for body mass index (BMI), as this measure is frequently used and widely adopted to define overweight/obesity. Subjects were defined as lean (BMI $<25, n=30)$, overweight $(25 \leq \mathrm{BMI}<30, \quad n=29) \quad$ or obese $\quad\left(\mathrm{BMI} \geq 30 \mathrm{~kg} / \mathrm{m}^{2}\right.$, $n=28)$ and were allocated to walk 30,40 or $50 \mathrm{~km}$ (Table 1). In addition, we also assessed body fat percentage and waist circumference as alternative markers of overweight/obesity. Written informed consent was obtained from all participants prior to the start of the study. This study was approved by the Medical Ethical Committee of the Radboud University Nijmegen Medical Centre, and was conducted in accordance with the Declaration of Helsinki.

\section{Experimental design}

Subjects participated in the International Nijmegen Four Days Marches, an annual walking event in The Netherlands, and walked $30 \mathrm{~km}(30 \%), 40 \mathrm{~km}(47 \%)$ or $50 \mathrm{~km}$
$(23 \%)$ at a self selected pace. $12-36 \mathrm{~h}$ prior to the start of the march, baseline measurements (subject characteristics, health and training status) were conducted under controlled conditions. $15 \mathrm{~min}$ prior to the exercise bout, heart rate and core body temperature were measured. During exercise, heart rate and core body temperature were measured every subsequent $5 \mathrm{~km}$. Immediately after finishing, all measurements were repeated.

\section{Measurements}

\section{Subject characteristics}

At baseline, body mass (Seca 888 scale, Hamburg, Germany) and height were measured in duplicate and BMI was calculated. A four-point skinfold thickness measurement (biceps, triceps, sub-scapular, supra-iliac) was obtained by a well-trained and highly experienced researcher to calculate the body fat percentage (Durnin and Womersley 1974). Waist circumference was measured midway between the lower rib margin and iliac crest. Hip circumference was measured at the level of widest circumference over the greater trochanters. Waist to-hip ratio was calculated as waist circumference divided by hip circumference. Resting heart rate and blood pressure were measured twice using an automated sphygmomanometer (M5-1 intellisense, Omron Healthcare, Hoofddorp, The Netherlands) after 5-min seated rest. Finally, all subjects completed a questionnaire about their physical activity (hours of sport participation per week), training status (walking-specific training history in the year preceding the walking march) and health status (presence of pathology and use of medication).

\section{Core body temperature}

Core body temperature was assessed using a portable telemetry system (CorTemp ${ }^{\mathrm{TM}}$ system, HQ Inc, Palmetto, USA), which has been demonstrated to be safe and reliable (Byrne and Lim 2007; Gant et al. 2006). Participants ingested an individually calibrated telemetric temperature sensor the evening preceding the experiment. Prior to the start of the exercise, core body temperature of each individual participant was measured using an external recorder. Baseline core body temperature was defined as the average of three consecutive measurements within $30 \mathrm{~s}$. Similarly, core body temperature was measured at every $5 \mathrm{~km}$ point during the march. The highest value of these measurements was presented as maximum core body temperature.

\section{Exercise intensity}

Heart rate was measured with a two-channel ECG chest band system (Polar Electro Oy, Kempele, Finland) simultaneously 
Table 1 Subject characteristics and details about the health status, presented per subgroup

\begin{tabular}{|c|c|c|c|c|}
\hline & $\mathrm{BMI}<25$ & $25 \leq \mathrm{BMI}<30$ & $\mathrm{BMI} \geq 30$ & $P$ value \\
\hline \multicolumn{5}{|l|}{ Demographic characteristics } \\
\hline Sex (men:women) & $15: 15$ & $15: 14$ & $25: 13$ & - \\
\hline Age (years) & $57 \pm 19$ & $56 \pm 11$ & $53 \pm 9$ & 0.53 \\
\hline Height $(\mathrm{cm})$ & $174 \pm 11$ & $174 \pm 9$ & $175 \pm 9$ & 0.84 \\
\hline Weight (kg) & $69.5 \pm 11.2$ & $83.5 \pm 8.1^{\mathrm{a}}$ & $101.4 \pm 10.7^{\mathrm{a}, \mathrm{b}}$ & $<0.001$ \\
\hline Body-mass index $\left(\mathrm{kg} / \mathrm{m}^{2}\right)$ & $22.8 \pm 1.9$ & $27.4 \pm 1.4^{\mathrm{a}}$ & $32.9 \pm 1.9^{\mathrm{a}, \mathrm{b}}$ & $<0.001$ \\
\hline Waist circumference $(\mathrm{cm})$ & $93 \pm 6$ & $102 \pm 6^{\mathrm{a}}$ & $111 \pm 7^{\mathrm{a}, \mathrm{b}}$ & $<0.001$ \\
\hline Waist to hip ratio & $0.91 \pm 0.07$ & $0.95 \pm 0.06$ & $0.99 \pm 0.07^{\mathrm{a}, \mathrm{b}}$ & $<0.001$ \\
\hline Body fat $(\%)$ & $29 \pm 6$ & $34 \pm 6^{\mathrm{a}}$ & $38 \pm 6^{\mathrm{a}, \mathrm{b}}$ & $<0.001$ \\
\hline Glucose $(\mathrm{mmol} / \mathrm{L})$ & $5.4 \pm 1.3$ & $5.4 \pm 0.5$ & $5.7 \pm 1.4$ & 0.41 \\
\hline Cholesterol (mmol/L) & $5.3 \pm 1.1$ & $5.4 \pm 1.1$ & $5.5 \pm 1.1$ & 0.85 \\
\hline Triglycerides (mmol/L) & $1.1 \pm 0.6$ & $1.5 \pm 0.6^{\mathrm{a}}$ & $1.5 \pm 0.8^{\mathrm{a}}$ & 0.07 \\
\hline High density lipoproteins (mmol/L) & $1.5 \pm 0.3$ & $1.2 \pm 0.2^{\mathrm{a}}$ & $1.2 \pm 0.3^{\mathrm{a}}$ & 0.001 \\
\hline Low density lipoproteins (mmol/L) & $3.3 \pm 0.9$ & $3.6 \pm 1.0$ & $3.6 \pm 1.0$ & 0.54 \\
\hline \multicolumn{5}{|l|}{ Health status } \\
\hline Mean distance trained $(\mathrm{km} / \mathrm{year})^{\mathrm{c}}$ & $578 \pm 651$ & $452 \pm 715$ & $633 \pm 587$ & 0.54 \\
\hline Mean arterial pressure (mm $\mathrm{Hg})$ & $98 \pm 11$ & $104 \pm 11$ & $107 \pm 13^{\mathrm{a}}$ & 0.011 \\
\hline Use of prescribed medicines (\%) & 47 & 62 & $82^{\mathrm{a}}$ & 0.010 \\
\hline Diuretics $(\%)$ & 3 & 3 & 16 & 0.10 \\
\hline Anti-hypertensive drugs (\%) & 13 & 24 & 37 & 0.09 \\
\hline Statins $(\%)$ & 10 & 10 & 16 & 0.71 \\
\hline Beta-blockers $(\%)$ & 7 & 7 & 13 & 0.57 \\
\hline Anti-diabetic drugs $(\%)$ & 3 & 0 & 11 & 0.13 \\
\hline Pathology $(\%)$ & 53 & 72 & 68 & 0.26 \\
\hline Hypertension (\%) & 20 & 24 & 37 & 0.27 \\
\hline Hypercholesterolemia (\%) & 13 & 10 & 21 & 0.45 \\
\hline Skin disease (\%) & 7 & 24 & 16 & 0.18 \\
\hline Osteoporosis (\%) & 10 & 10 & 5 & 0.69 \\
\hline Asthma (\%) & 3 & 14 & 16 & 0.24 \\
\hline Diabetes $(\%)$ & 3 & 0 & 11 & 0.13 \\
\hline
\end{tabular}

a, b Post-hoc significant difference in relation to lean and overweight subjects respectively

${ }^{c}$ Ln-transformation was applied as a non-Gaussian distribution was present

with core body temperature (i.e. every $5 \mathrm{~km}$ point, 3 consecutive measurements which were taken within $30 \mathrm{~s}$ ), using the same data recorder. Mean heart rate during exercise was calculated as the average heart rate, excluding the values derived directly before the start and after the finish. Exercise intensity was calculated by dividing the mean heart rate during exercise by the maximal predicted heart rate (208-0.7 age) (Tanaka et al. 2001). Subsequently, exercise intensity was presented as a percentage of maximal heart rate $\left(\% \mathrm{HR}_{\max }\right)$.

\section{Blood analysis}

Ten $\mathrm{ml}$ of venous blood were drawn from an antecubital vein at baseline and directly after finishing. Whole venous blood was collected in serum-gel vacutainer tubes and allowed to clot for $\sim 45 \mathrm{~min}$. After centrifugation, serum was aliquoted, frozen and stored at $-80^{\circ} \mathrm{C}$ for later analysis. Analysis was performed on a single day using the same calibration and set-up to minimize variation. cTnI was analysed using a highly-sensitive cTnI-assay (Centaur TnI-Ultra, Siemens Healthcare Diagnostics, Breda, The Netherlands). The assay imprecision of the highly-sensitive cTnI-assay was $5.3 \%$ at $0.08 \mu \mathrm{g} / \mathrm{L}$ and $3.0 \%$ at $27.2 \mu \mathrm{g} / \mathrm{L}$. A cTnI-value of $0.04 \mu \mathrm{g} / \mathrm{L}$ is the clinical cut-off value for myocardial infarction (Apple et al. 2008).

\section{Ambient conditions}

Throughout the experiment, dry bulb, wet bulb, and globe temperatures were measured every $30 \mathrm{~min}$ using a portable climate monitoring device (Davis instruments inc., 
Table 2 Exercise characteristics per BMI group

\begin{tabular}{lllll}
\hline & BMI $<25$ & $25 \leq \mathrm{BMI}<30$ & $\mathrm{BMI} \geq 30$ & $P$ value \\
\hline $\begin{array}{l}\text { Exercise characteristics } \\
\text { Walking distance }\end{array}$ & & & \\
$30(\mathrm{~km})$ & 34 & 34 & 24 & 0.87 \\
$40(\mathrm{~km})$ & 43 & 45 & 52 & \\
$50(\mathrm{~km})$ & 23 & 21 & 24 & \\
Exercise duration $(\mathrm{hh}: \mathrm{mm})$ & $8: 32 \pm 1: 58$ & $8: 39 \pm 1: 25$ & $8: 48 \pm 1: 23$ & 0.79 \\
Speed $(\mathrm{km} / \mathrm{h})$ & $4.8 \pm 0.7$ & $4.7 \pm 0.8$ & $4.7 \pm 0.7$ & 0.69 \\
Baseline core body temperature $\left({ }^{\circ} \mathrm{C}\right)$ & $37.5 \pm 0.4$ & $37.6 \pm 0.5$ & $37.5 \pm 0.3$ & 0.55 \\
Maximum core body temperature $\left({ }^{\circ} \mathrm{C}\right)$ & $38.3 \pm 0.3$ & $38.4 \pm 0.3$ & $38.5 \pm 0.3$ & 0.053 \\
Exercise intensity $\left(\% \mathrm{HR}_{\max }\right)$ & $71 \pm 9$ & $71 \pm 10$ & $74 \pm 8$ & 0.30 \\
\hline
\end{tabular}

Hayward, USA) positioned at the start/finish area. The wet bulb globe temperature index (WBGT) was calculated using the formula: $\mathrm{WBGT}=0.1\left(T_{\text {dry bulb }}\right)+0.7\left(T_{\text {wet bulb }}\right)+0.2$ $\left(T_{\text {globe }}\right)$ (Armstrong et al. 2007).

\section{Statistical analysis}

All values were presented as mean \pm standard deviation, unless indicated otherwise. Statistical analyses were performed using SPSS 16.0 (SPSS, Chicago, IL, USA). The level of statistical significance was set at $P<0.05$. The normality of the data distribution was examined by the Kolmogorov-Smirnov test. When data demonstrated a non-Gaussian distribution, Ln-transformation was applied. Comparisons between groups were assessed using a oneway ANOVA for continuously distributed data. A two-way repeated measures ANOVA was applied to examine the change in cTnI after exercise in the three distinct groups (exercise $\times$ group). Post hoc $t$ tests with the Least Square Difference correction for multiple comparisons were performed when the ANOVA reported a significant main or interaction effect. A backward stepwise linear regression analysis was used to identify factors that significantly relate to post-exercise cTnI-levels. We have included BMI, age, sex, exercise intensity and pre-existing cardiovascular pathology as potential determinants of post-exercise cTnIlevels as previous studies have demonstrated evidence that these factors may relate to exercise-induced cTnI release (Eijsvogels et al. 2010; Shave et al. 2007b). In addition, we replaced BMI with two alternative measures of obesity (fat percentage and waist circumference) in the regression analysis to further assess the effect of obesity on post-exercise cTnI levels. Finally, using the same sets of parameters, a binary logistic regression analysis was used to identify factors that contribute to the positive cTnI-samples (cTn $>$ URL). The odds ratio (OR) and 95\% confidence interval (CI) were presented for those factors that were identified as significant factors to contribute to a positive cTnI-sample.

\section{Results}

The three BMI groups were not different in age and height, but as expected differed significantly in weight, BMI, body surface area, waist circumference and body fat percentage (Table 1). Participation in sports activities and the distance trained was not different across groups (Table 1), but the average training distance of $560 \mathrm{~km}$ suggested that our subjects were well prepared for the walking march. No differences in the prevalence of (cardiovascular) pathology were found (Table 1). Obese subjects, however, showed a higher mean arterial pressure and used more prescribed medication than their lean counterparts (Table 1).

\section{Exercise characteristics}

All subjects successfully completed the exercise bout. The WBGT increased from $14.0^{\circ} \mathrm{C}$ in the morning to a maximum of $25.0^{\circ} \mathrm{C}$ in the afternoon. Walking speed did not significantly differ across groups (Table 2). Baseline and maximum core body temperature during exercise were not different between lean, overweight, and obese subjects, whilst also exercise intensity $\left(\% \mathrm{HR}_{\max }\right)$ was comparable across groups (Table 2).

\section{Cardiac troponin}

Ln-transformation was applied to the cTnI data set, as a non-Gaussian distribution was found. Baseline cTnI levels were not different across the three groups. The two-way ANOVA revealed a significant increase in cTnI from $0.010 \pm 0.006$ to $0.024 \pm 0.046 \mu \mathrm{g} / \mathrm{L}$ after exercise $(P<0.001)$ (Fig. 1). However, the magnitude of the exercise-induced increase in cTnI in lean (pre: $0.009 \pm 0.007$, post: $0.014 \pm 0.010 \mu \mathrm{g} / \mathrm{L}$ ) was not different from overweight (pre: $0.012 \pm 0.008$, post: $0.040 \pm 0.085 \mu \mathrm{g} / \mathrm{L}$ ) or obese subjects (pre: $0.009 \pm 0.005$, post: $0.021 \pm 0.016 \mu \mathrm{g} / \mathrm{L}$ ) (Fig. 1). To gain further insight into factors that contribute to cTnI-release, a backward linear regression analysis 


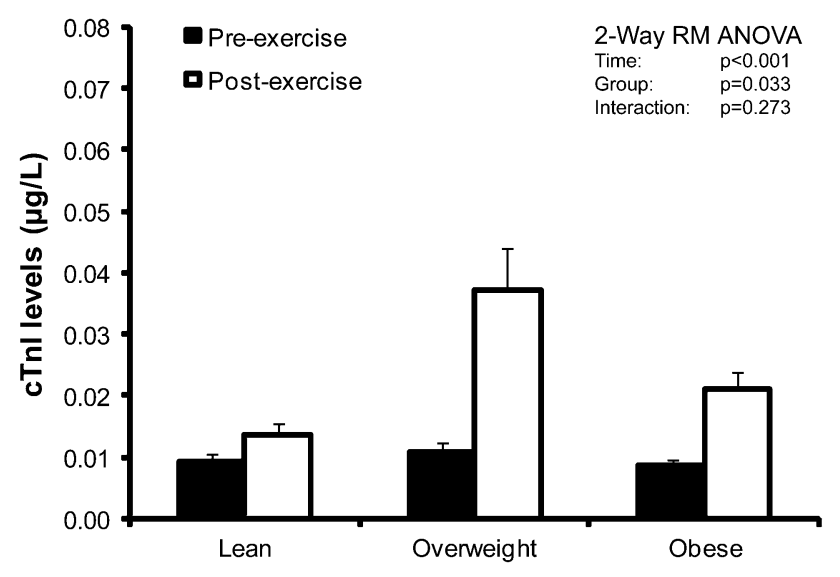

Fig. 1 Pre- (black bars) and post-exercise (white bars) cTnI levels in lean (BMI $\left.<25 \mathrm{~kg} / \mathrm{m}^{2}, n=30\right)$, overweight $\left(25 \leq \mathrm{BMI}<30 \mathrm{~kg} / \mathrm{m}^{2}\right.$, $n=29)$ and obese subjects (BMI $\left.\geq 30 \mathrm{~kg} / \mathrm{m}^{2}, n=38\right)$. Two-way RM ANOVA revealed a significant time $(P<0.001)$ and group $(P=0.033)$ effect. However, no interaction was present (time $\times$ group, $P=0.27$ ) which indicates that the exercise-induced increase in cTnI was not significantly different across groups. Error bars represent SE

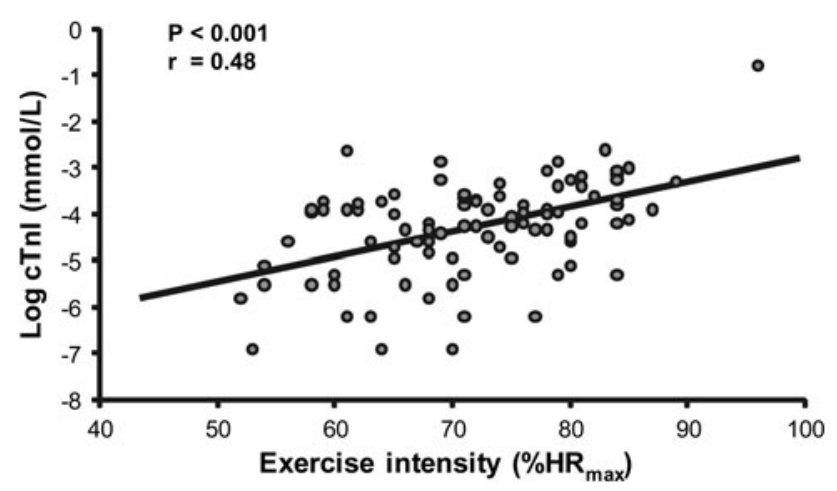

Fig. 2 Correlation between exercise intensity (expressed as percentage of maximum predicted heart rate) and Ln-transformed cardiac troponin I levels (cTnI). An increase in exercise intensity is significantly related to higher levels of $\mathrm{cTnI}(P<0.001, r=0.48)$

identified age $(\beta=0.27, P=0.003)$, sex $(\beta=-0.19$, $P=0.031)$ and exercise intensity $\left(\% \mathrm{HR}_{\max }, \beta=0.47\right.$, $P<0.001$, Fig. 2), but not BMI and pre-existing cardiovascular pathology, as significant predictors of post-exercise cTnI-level $\left(r^{2}=0.38, P<0.001\right)$. Using fat percentage as a marker for obesity, we identified the same predictor variables with a comparable total predicted variance $\left(r^{2}=0.36\right.$, $P<0.001$ ). Also using waist circumference we found the same total predicted variance $\left(r^{2}=0.38, P<0.001\right)$, and confirmed the predictive capacity of age $(\beta=0.31$, $P<0.001)$ and exercise intensity $\left(\% \mathrm{HR}_{\max }, \beta=0.43\right.$, $P<0.001)$. However, waist circumference $(\beta=0.22$, $P<0.01)$ replaced sex as a significant predictor.

Eleven of our participants ( 9 male, 2 female) showed a cTnI level above the AMI cut-off (cTn $>$ URL). A Chisquare test revealed that the presence of $c T n>U R L$
Table 3 Subject characteristics and cardiovascular risk factors in subjects with a cTnI level below $(\mathrm{cTn}<\mathrm{URL})$ and above $(\mathrm{cTn}>\mathrm{URL})$ the clinical cut-off value for AMI

\begin{tabular}{llll}
\hline & cTn $<$ URL & cTn $>$ URL & $P$ value \\
\hline Sex (men:women) & $46: 40$ & $9: 2$ & 0.074 \\
Age (yr) & $55 \pm 14$ & $54 \pm 8$ & 0.78 \\
Body-mass index $\left(\mathrm{kg} / \mathrm{m}^{2}\right)$ & $28.0 \pm 4.7$ & $29.4 \pm 3.9$ & 0.32 \\
Fat percentage $(\%)$ & $34 \pm 7$ & $34 \pm 6$ & 0.84 \\
Waist circumference $(\mathrm{mm})$ & $97 \pm 13$ & $105 \pm 11$ & 0.13 \\
Exercise intensity $(\%)$ & $71 \pm 9$ & $80 \pm 9$ & 0.003 \\
Use of prescribed medicines $(\%)$ & 67 & 45 & 0.15 \\
Hypertension $(\%)$ & 29 & 18 & 0.45 \\
Hypercholesterolemia $(\%)$ & 17 & 0 & 0.13 \\
Diabetes $(\%)$ & 6 & 0 & 0.41 \\
Smoking $(\%)$ & 7 & 18 & 0.21
\end{tabular}

A students $T$ Test (continuous parameters) and a Chi Square test (binominal parameters) were used to compare cTn $<$ URL with $\mathrm{cTn}>\mathrm{URL}$

differed between lean, overweight and obese subjects $(n=0,7$ and 4, respectively, $P=0.014)$. However, subjects with $\mathrm{cTnI}<\mathrm{ULR}$ and $\mathrm{cTnI}>\mathrm{URL}$ did not differ in age, BMI, fat percentage or waist circumference (corrected for sex) or presence of diseases (i.e. hypertension, hypercholesterolemia and diabetes), whilst exercise intensity was significantly higher in subjects with cTn $>$ URL (Table 3 ). Using binary logistic regression analysis, we found that exercise intensity $\left(\% \mathrm{HR}_{\max }, P<0.01, \mathrm{OR}=1.1, \mathrm{CI}: 1.0\right.$ 1.3) was associated with a $\mathrm{cTn}>\mathrm{URL}$. This finding was present, independent of using BMI, fat percentage or waist circumference as a measure of obesity in our model.

\section{Discussion}

This is the first study, to our knowledge, to directly examine the impact of obesity on cTnI-release during prolonged exercise. Our results indicate that prolonged moderateintensity walking exercise significantly elevates cTnI-levels in asymptomatic subjects. More importantly, and in contrast to our hypothesis, the magnitude of the absolute cTnIincrease was comparable between lean, overweight, and obese subjects. When using the cTnI cut-off level for diagnosis of AMI (Thygesen et al. 2007), 11\% of our asymptomatic participants demonstrated a positive test. Nonetheless, our statistical analysis revealed that these positive cTnI tests could not be explained through measures of obesity (BMI, body fat percentage or waist circumference).

Analysis of cTnI is recommended as a sensitive and specific marker for cardiac damage in the diagnosis of AMI (Morrow et al. 2007; Thygesen et al. 2007; Wu 2009). 
The observation that cTnI-levels were elevated after exercise in lean, overweight and obese subjects, with even $11 \%$ of our population $(n=11)$ exceeding the cut-off value for AMI, is highly clinically relevant. Whilst previous studies predominantly focused on cTnI-levels in athletes after high-intensity exercise (Dawson et al. 2008; George et al. 2004; Middleton et al. 2008; Scharhag et al. 2005), we showed that prolonged moderate-intensity walking exercise ( $72 \%$ of the maximal predicted heart rate) can lead to significant elevations of post-exercise cTnI in a heterogeneous group of asymptomatic humans.

We found that the exercise-induced increase in $\mathrm{cTnI}$ is comparable between lean, overweight, and obese subjects. This suggests that, in contrast to our hypothesis, obesity does not affect the magnitude of post-exercise cTnI elevation. Indeed, linear regression analysis using various measures of obesity (i.e. BMI, fat percentage and waist circumference) identified that exercise intensity, age and sex significantly contribute to the post-exercise cTnI level. Although one of the models replaced sex with waist circumference, this finding may be confounded by the co-linearity between these measures. In addition, 9 of the 11 subjects with cTnI-levels above the clinical cut-off value were men who typically demonstrate a larger waist circumference than women. Furthermore, we demonstrated that BMI, body fat percentage, and waist circumference were not different between subjects with and without a positive cTnI test, whilst the binary logistic regression analysis identified exercise intensity as a predictor of a positive cTnI sample. Taken together, our data suggests that obesity unlikely contributes to the magnitude of the post-exercise elevation in cTnI.

Although obesity may not alter the magnitude of the exercise-induced increase in cTnI, our observation does not necessarily invalidate the hypothesis that subjects with cardiovascular risk may demonstrate a larger exercise-induced increase in cTnI. Indeed, we identified advanced age and male sex, i.e. both well-established cardiovascular risk factors, as independent predictors for the magnitude of the exercise-induced increase in cTnI. Interestingly, a recent multivariable regression analysis identified age and sex, but also fasting glucose and NT-proBNP, as significant predictors for resting $\mathrm{cTnT}$ in the general community (Xu et al. 2011). This provides indirect support for the above hypothesis. In addition, since we performed this study, there is evolving evidence that cardiovascular risk factors than obesity (e.g. diabetes mellitus and hypertension) have a more profound effect on resting cTn-levels (deFilippi et al. 2010; Xu et al. 2011). Unfortunately, due to the selection criteria for our study, subgroups with diabetes and/or cardiovascular risk in our study are too small to perform meaningful statistical analysis. We strongly support future studies to examine whether other cardiovascular risk factors than obesity influence the exercise-induced elevation in cTn.

Elevated cTnI levels are suggestive for cardiac damage, but the average cTnI increase in our study was small and was not associated with symptoms of cardiac injury. It may well be possible that the increase in cTnI did not reflect irreversible ischemic myocardial "damage", but relates to a physiological response during prolonged exercise. The elevated heart rate during exercise may cause an increased mechanical stress on the heart, possibly leading to an increased release of cTnI. Interestingly, our study identified exercise intensity as the strongest predictor for the increase of cTnI levels, but also for a positive cTnI test. Exercise intensity, and the associated increased myocardial work, may therefore contribute to $\mathrm{cTnI}$-release during prolonged moderate-intensity exercise. These findings are in agreement with a recent paper that found that exercise intensity influenced the magnitude of the troponin response during marathon running (Legaz-Arrese et al. 2011). Moreover, the increased myocardial work can also transiently accelerate the constant process of apoptosis and regeneration in the myocardium (Beltrami et al. 2003). The very small amounts of cardiac 'damage' are subsequently repaired as part of the normal regenerative capacity of the myocardium, but would also cause a temporal increase in cTnI levels post-exercise. A last explanation relates to an impaired clearance of troponin from the circulation. Blood flow in the abdominal area and kidneys reduces markedly during exercise (Qamar and Read 1987; Suzuki et al. 1996; Thijssen et al. 2009). Consequently, the kidneys capacity to secrete substances is attenuated (Suzuki et al. 1996), possibly resulting in a small increase in cTnI concentration in the blood.

\section{Limitations}

The strengths of this study are the inclusion of a large group of participants, the unique study design and completion of a prolonged exercise bout. Due to practical limitations, we did not determine maximal heart rate, but used a previously validated and frequently used model to predict maximal heart rate (Tanaka et al. 2001). A limitation is our single post-exercise assessment of cTnI, as previous observations reported a time-dependent change in cTnI after a marathon (Middleton et al. 2008). It is currently unknown whether obesity alters the time-course of cTnI-release after exercise and, therefore, potentially alters our findings. In addition, it must be noted the coefficient of variation increases when measuring at the lower end of the cTnI spectrum. However, excluding subjects with low values (i.e. below $0.006 \mu \mathrm{g} / \mathrm{L}$ ) did not alter the major outcomes of our study.

In conclusion, prolonged exercise resulted in a significant increase in cTnI-levels in asymptomatic lean, over- 
weight, and obese subjects. The magnitude of the exerciseinduced increase in cTnI was not different among lean, obese, and overweight subjects and relates predominantly to age, gender and exercise intensity. These findings were reinforced by our subjects with a cTnI above the clinical cut-off level, as their BMI, fat percentage and waist circumference was comparable with subjects below this level. Therefore, obesity unlikely contributes to the magnitude of the post-exercise elevation in cTnI.

Acknowledgments We recognize the excellent help of the organization of the International Nijmegen Four Days Marches, Siemens Medical Solutions Diagnostics B.V. (Breda, The Netherlands), Noortje van Duijnhoven, Ralph Scholten, Madelijn Sander, Bregina Kersten, Fleur Poelkens, Tim Schreuder and Linda Pardoel. Dr. Thijssen is financially supported by The Netherlands Heart Foundation (E. Dekker-stipend 2009/065)

\section{Conflict of interest None.}

Open Access This article is distributed under the terms of the Creative Commons Attribution Noncommercial License which permits any noncommercial use, distribution, and reproduction in any medium, provided the original author(s) and source are credited.

\section{References}

Apple FS, Smith SW, Pearce LA, Ler R, Murakami MM (2008) Use of the Centaur TnI-Ultra assay for detection of myocardial infarction and adverse events in patients presenting with symptoms suggestive of acute coronary syndrome. Clin Chem 54:723-728

Armstrong LE, Casa DJ, Millard-Stafford M, Moran DS, Pyne SW, Roberts WO (2007) American College of Sports Medicine position stand. Exertional heat illness during training and competition. Med Sci Sports Exerc 39:556-572

Beltrami AP, Barlucchi L, Torella D, Baker M, Limana F, Chimenti S, Kasahara H, Rota M, Musso E, Urbanek K, Leri A, Kajstura J, Nadal-Ginard B, Anversa P (2003) Adult cardiac stem cells are multipotent and support myocardial regeneration. Cell 114:763776

Byrne C, Lim CL (2007) The ingestible telemetric body core temperature sensor: a review of validity and exercise applications. $\mathrm{Br} \mathrm{J}$ Sports Med 41:126-133

Daniels LB, Laughlin GA, Clopton P, Maisel AS, Barrett-Connor E (2008) Minimally elevated cardiac troponin $\mathrm{T}$ and elevated $\mathrm{N}$-terminal pro-B-type natriuretic peptide predict mortality in older adults: results from the Rancho Bernardo Study. J Am Coll Cardiol 52:450-459

Dawson EA, Whyte GP, Black MA, Jones H, Hopkins ND, Oxborough D, Gaze D, Shave RE, Wilson M, George KP, Green DJ (2008) Changes in vascular and cardiac function after prolonged strenuous exercise in humans. J Appl Physiol 105(5):1562-1568

de Lemos JA, Drazner MH, Omland T, Ayers CR, Khera A, Rohatgi A, Hashim I, Berry JD, Das SR, Morrow DA, McGuire DK (2010) Association of troponin T detected with a highly sensitive assay and cardiac structure and mortality risk in the general population. JAMA 304:2503-2512

deFilippi CR, de Lemos JA, Christenson RH, Gottdiener JS, Kop WJ, Zhan M, Seliger SL (2010) Association of serial measures of cardiac troponin $\mathrm{T}$ using a sensitive assay with incident heart fail- ure and cardiovascular mortality in older adults. JAMA 304:2494-2502

Durnin JV, Womersley J (1974) Body fat assessed from total body density and its estimation from skinfold thickness: measurements on 481 men and women aged from 16 to 72 years. Br J Nutr 32:77-97

Eijsvogels T, George K, Shave R, Gaze D, Levine BD, Hopman MT, Thijssen DH (2010) Effect of prolonged walking on cardiac troponin levels. Am J Cardiol 105:267-272

Everett BM, Cook NR, Magnone MC, Bobadilla M, Kim E, Rifai N, Ridker PM, Pradhan AD (2011) Sensitive cardiac troponin T assay and the risk of incident cardiovascular disease in women with and without diabetes mellitus: the Women's Health Study. Circulation 123:2811-2818

Gant N, Atkinson G, Williams C (2006) The validity and reliability of intestinal temperature during intermittent running. Med Sci Sports Exerc 38:1926-1931

Gelber RP, Gaziano JM, Orav EJ, Manson JE, Buring JE, Kurth T (2008) Measures of obesity and cardiovascular risk among men and women. J Am Coll Cardiol 52:605-615

George K, Whyte G, Stephenson C, Shave R, Dawson E, Edwards B, Gaze D, Collinson P (2004) Postexercise left ventricular function and cTnT in recreational marathon runners. Med Sci Sports Exerc $36: 1709-1715$

James WP (2008) WHO recognition of the global obesity epidemic. Int J Obesity 32 (Suppl 7): S120-S126

Koller A (2003) Exercise-induced increases in cardiac troponins and prothrombotic markers. Med Sci Sports Exerc 35:444-448

Kragelj R, Jarm T, Miklavcic D (2000) Reproducibility of parameters of postocclusive reactive hyperemia measured by near infrared spectroscopy and transcutaneous oximetry. Ann Biomed Eng 28:168-173

Legaz-Arrese A, George K, Carranza-Garcia LE, Munguia-Izquierdo D, Moros-Garcia T, Serrano-Ostariz E (2011) The impact of exercise intensity on the release of cardiac biomarkers in marathon runners. Eur J Appl Physiol (epub ahead of print)

Middleton N, George K, Whyte G, Gaze D, Collinson P, Shave R (2008) Cardiac troponin $\mathrm{T}$ release is stimulated by endurance exercise in healthy humans. J Am Coll Cardiol 52:1813-1814

Morrow DA, Cannon CP, Jesse RL, Newby LK, Ravkilde J, Storrow AB, Wu AH, Christenson RH (2007) National Academy of Clinical Biochemistry Laboratory Medicine Practice Guidelines: clinical characteristics and utilization of biochemical markers in acute coronary syndromes. Circulation 115:e356-e375

Neumayr G, Pfister R, Mitterbauer G, Eibl G, Hoertnagl H (2005) Effect of competitive marathon cycling on plasma N-terminal probrain natriuretic peptide and cardiac troponin $\mathrm{T}$ in healthy recreational cyclists. Am J Cardiol 96:732-735

Qamar MI, Read AE (1987) Effects of exercise on mesenteric blood flow in man. Gut 28:583-587

Saunders JT, Nambi V, de Lemos JA, Chambless LE, Virani SS, Boerwinkle E, Hoogeveen RC, Liu X, Astor BC, Mosley TH, Folsom AR, Heiss G, Coresh J, Ballantyne CM (2011) Cardiac troponin $\mathrm{T}$ measured by a highly sensitive assay predicts coronary heart disease, heart failure, and mortality in the Atherosclerosis Risk in Communities Study. Circulation 123:1367-1376

Scharhag J, Herrmann M, Urhausen A, Haschke M, Herrmann W, Kindermann W (2005) Independent elevations of N-terminal probrain natriuretic peptide and cardiac troponins in endurance athletes after prolonged strenuous exercise. Am Heart $\mathbf{J}$ 150:1128-1134

Shave R, Baggish A, George K, Wood M, Scharhag J, Whyte G, Gaze D, Thompson PD (2010) Exercise-induced cardiac troponin elevation: evidence, mechanisms, and implications. J Am Coll Cardiol 56:169-176 
Shave R, George K, Gaze D (2007a) The influence of exercise upon cardiac biomarkers: a practical guide for clinicians and scientists. Curr Med Chem 14:1427-1436

Shave R, George KP, Atkinson G, Hart E, Middleton N, Whyte G, Gaze D, Collinson PO (2007b) Exercise-induced cardiac troponin T release: a meta-analysis. Med Sci Sports Exerc 39:2099-2106

Suzuki M, Sudoh M, Matsubara S, Kawakami K, Shiota M, Ikawa S (1996) Changes in renal blood flow measured by radionuclide angiography following exhausting exercise in humans. Eur J Appl Physiol Occup Physiol 74:1-7

Tanaka H, Monahan KD, Seals DR (2001) Age-predicted maximal heart rate revisited. J Am Coll Cardiol 37:153-156

Thijssen DH, Steendijk S, Hopman MT (2009) Blood redistribution during exercise in subjects with spinal cord injury and controls. Med Sci Sports Exerc 41:1249-1254

Thygesen K, Alpert JS, White HD, Jaffe AS, Apple FS, Galvani M, Katus HA, Newby LK, Ravkilde J, Chaitman B, Clemmensen PM, Dellborg M, Hod H, Porela P, Underwood R, Bax JJ, Beller GA, Bonow R, Van der Wall EE, Bassand JP, Wijns W, Ferguson TB, Steg PG, Uretsky BF, Williams DO, Armstrong PW, Antman EM, Fox KA, Hamm CW, Ohman EM, Simoons ML, PooleWilson PA, Gurfinkel EP, Lopez-Sendon JL, Pais P, Mendis S, Zhu JR, Wallentin LC, Fernandez-Aviles F, Fox KM, Parkhomenko AN, Priori SG, Tendera M, Voipio-Pulkki LM,
Vahanian A, Camm AJ, De Caterina R, Dean V, Dickstein K, Filippatos G, Funck-Brentano C, Hellemans I, Kristensen SD, McGregor K, Sechtem U, Silber S, Tendera M, Widimsky P, Zamorano JL, Morais J, Brener S, Harrington R, Morrow D, Lim M, Martinez-Rios MA, Steinhubl S, Levine GN, Gibler WB, Goff D, Tubaro M, Dudek D, Al-Attar N (2007) Universal definition of myocardial infarction. Circulation 116:2634-2653

Wallace TW, Abdullah SM, Drazner MH, Das SR, Khera A, McGuire DK, Wians F, Sabatine MS, Morrow DA, de Lemos JA (2006) Prevalence and determinants of troponin $\mathrm{T}$ elevation in the general population. Circulation 113:1958-1965

Whyte G, Stephens N, Senior R, George K, Shave R, Wilson M, Sharma S (2007) Treat the patient not the blood test: the implications of an increase in cardiac troponin after prolonged endurance exercise. British journal of sports medicine 41:613-615; discussion 615

Wu AH (2009) Interpretation of high sensitivity cardiac troponin I results: reference to biological variability in patients who present to the emergency room with chest pain: case report series. Clin Chim Acta Int J Clin Chem 401:170-174

Xu R, Ye P, Luo L, Xiao W, Sheng L, Wu H, Bai J, Dong Z, Deng X (2011) Association between high-sensitivity cardiac troponin $T$ and predicted cardiovascular risks in a community-based population. Int J Cardiol 149:253-256 